\title{
O DESAFIO DA ESTRUTURAÇÃO DA CADEIA PRODUTIVA DO AMENDOIM NO SEMIÁRIDO DO NORDESTE
}

\author{
The Challenge of Structuring the Peanut Supply Chain in the Northeastern Semiarid Region of Brazil
}

\section{RESUMO}

A produção de amendoim no Brasil é fortemente concentrada no Estado de São Paulo. O potencial de consumo do Nordeste Brasileiro desperta o interesse em entender as possibilidades de se fortalecer a cadeia produtiva para este produto na região. Objetivou-se neste artigo descrever a cadeia produtiva do amendoim na região do reservatório de Itaparica (conhecido como Sistema Itaparica) entre os Estados de Pernambuco e Bahia, e trazer propostas que venham a auxiliar o produtor rural local no fortalecimento da sua posição dentro desta cadeia. Trata-se de um artigo qualitativo baseado em dados primários, utilizando-se de observação participativa e entrevistas não estruturadas como ferramentas de coleta de dados. Este trabalho é resultado do projeto de pesquisa "Sistema de Produção de Amendoim no Vale do São Francisco", liderado pela Embrapa Algodão e Noble Agri. Verifica-se que a cadeia está atualmente dedicada à comercialização do chamado amendoim verde em pequena escala e baseado em um sistema de produção rudimentar. Fortalecer a cadeia é fundamental para que ela possa entregar uma variedade maior de produtos in natura e processados e em volumes e frequência superiores aos atuais. Para tanto, quatro ações são sugeridas nos campos da tecnologia de produção, financiamentos, logística e associativismo/cooperativismo.

Daniel Franco Goulart

Universidade Presbiteriana Mackenzie

goulartdf@gmail.com

Raul Porfírio de Almeida

Empresa Brasileira de Pesquisa Agropecuária

raul.almeida@embrapa.br

Kallienny Costa Resende

Noble Agri

kallienny@gmail.com

Fernando Antônio Melo da Costa

Universidade Federal de Campina Grande

fmelocosta@gmail.com

José Renato Cortez Bezerra

Empresa Brasileira de Pesquisa Brasileira

jose.cortez-bezerra@embrapa.br

Recebido em: 02/03/2016. Aprovado em: 03/05/2017

Avaliado pelo sistema double blind review

Avaliador científico: Daniel Carvalho de Rezende

DOI: 10.21714/2238-68902017v19n1p047

\begin{abstract}
Peanuts production in Brazil is strongly concentrated in the State of São. This situation calls the attention aiming to understand the possibilities of strengthening the supply chain in this region. The targets of this paper are to describe peanut supply chain in the region of Itaparica System between the States of Bahia and Pernambuco and to come up with suggestions to strengthen local farmers' position in this supply chain. This is a qualitative paper based on primary data. Participative observation and non-structured interviews were used as data collection tools. This work is one of the outcomes from the research project "Peanuts Production System in São Francisco Valley, Brazil", led by Embrapa Algodão and Noble Agri. Nowadays this supply chain is built to trade a specific kind of peanut named "amendoim verde" (pre-matured or fresh peanut) in small scale and based on a very rudimentary production system. Key to strengthen this supply chain is to support it in delivering a wider sort of fresh and processed products and in increasing volume and improving frequency. To this end, four actions are suggested regarding to the following fields: production technology, financing, logistics and associative/cooperative forms of organization.
\end{abstract}

Palavras-chaves: Cadeia de Suprimentos, Produção Agrícola, Comercialização.

Keywords: Suplly Chain, Agricultural Production, Commercialization.

\section{INTRODUÇÃO}

O rigor do clima seco na região semiárida do Nordeste é, não raro, apontado como causa do insucesso em empreendimentos agrícolas. De fato, os baixos índices pluviométricos associados à sua distribuição irregular têm papel importante na derrocada da produção agrícola nesta região. Por outro lado, polos agrícolas dedicados à fruticultura e mesmo à produção de cana despontam de forma robusta na mesma região. Estas áreas desfrutam 
de irrigação proveniente de rios importantes que correm pela região, entre eles o São Francisco e o Parnaíba. Neste cenário, o clima seco deixa de ser um limitante à produção para se tornar fator importante de vantagem competitiva.

A pergunta que pode surgir é: mesmo com a disponibilidade de água para a irrigação, como pode o clima seco se tornar elemento de vantagem competitiva? O produtor possui maior ingerência na disponibilização de água à cultura nos momentos em que ela realmente precisa ao longo do seu ciclo de desenvolvimento. Da mesma forma, o produtor pode cessar o suprimento hídrico no momento em que assim se fizer necessário. Este padrão de qualidade no manejo pode proporcionar, por exemplo, elevação da produtividade, uso de defensivos agrícolas em menor quantidade e qualidade superior dos produtos colhidos.

A cultura do amendoim requer, na sua fase de colheita, umidade de solo suficiente para que o processo de arranque seja feito sem grandes quebras, seguida de uma fase sem chuvas de quatro a cinco dias, para que o amendoim possa secar no campo. Incidência de chuvas ou umidade na etapa pós-colheita tem grande potencial para comprometer a qualidade do produto. São Paulo, o principal Estado produtor do país, cultiva amendoim predominantemente em sistema não irrigado, estando, portanto, à mercê da variabilidade de clima. As áreas do semiárido do Nordeste que se beneficiam da irrigação são capazes de proporcionar um controle muito maior sobre a variável "clima".

No que se refere à comercialização, a demanda por amendoim do Nordeste é suprida pelo Estado de São Paulo. Um polo produtor perene e robusto no Nordeste assumiria uma posição de vantagem competitiva importante se comparado com São Paulo. Para fins de exercício de comparação, verifica-se que a distância entre Jaboticabal (SP), uma das principais cidades produtoras da oleaginosa, e Fortaleza (CE), uma das principais capitais do Nordeste é de $2.850 \mathrm{~km}$. Por outro lado, a distância entre Petrolândia (PE), às margens do reservatório de Itaparica, no Rio São Francisco, e a mesma capital é de $787 \mathrm{~km}$. São praticamente $2.000 \mathrm{~km}$ de diferença que fazem toda a diferença em qualquer cadeia produtiva.

O potencial do Nordeste para o estabelecimento de uma cadeia produtiva que possa atender de forma competitiva à demanda dessa região motivou a fundação do projeto de pesquisa "Sistema de Produção de Amendoim no Vale do São Francisco". Sob a abrangência deste projeto, propõe-se, no presente estudo, descrever a cadeia produtiva do amendoim na região do reservatório de
Itaparica (conhecido como Sistema Itaparica) entre os Estados de Pernambuco e Bahia e trazer propostas que venham a auxiliar o produtor rural local no fortalecimento da sua posição dentro desta cadeia.

Trata-se de um artigo qualitativo elaborado a partir de dados primários coletados em campo. Observações participativas e questionários não estruturados são utilizados como ferramentas de coleta de dados, conforme prevê Godoy (1995). Utiliza-se dos conceitos sobre cadeias produtivas e gestão da cadeia de suprimentos como ferramental teórico para a construção das discussões. Conceitos relacionados à competitividade de cadeias de suprimentos são, de igual maneira, fundamentais para o desenvolvimento deste trabalho.

Trabalhos que se apoiam nos conceitos de gestão da cadeia de suprimentos e cadeias produtivas são comuns na literatura sobre agronegócio. Zylbersztajn; Filho (2003) utilizam a cadeia de suprimentos da carne para discutir a relação entre coordenação da cadeia e vantagem competitiva. Ji et al. (2012) discutem a estrutura de governança na cadeia de suprimento suína na China a partir dos constructos gestão da cadeia de suprimentos, custos de transação e análise de valor. Neste artigo, buscase construir o mesmo tipo de discussão para a cadeia produtiva do amendoim.

As discussões realizadas ao longo deste trabalho são centradas em três aspectos: a caracterização da produção de amendoim no Brasil, a caracterização da cadeia produtiva do amendoim na região do Sistema Itaparica e as ações a serem tomadas para que a posição do pequeno agricultor local seja fortalecida na referida cadeia.

\section{REFERENCIAL TEÓRICO: CADEIAS PRODUTIVAS E GESTÃO DA CADEIA DE SUPRIMENTOS}

O conjunto dos fluxos físicos, financeiros e de informações entre agentes envolvidos com um produto específico e seus processos de agregação de valor é denominado de cadeia produtiva. Batalha (1995) enuncia que "a arquitetura da representação do sistema [cadeia] é o resultado do encadeamento das operações técnicas (de montante à jusante) que refletem a sequência de transformação das matérias-primas em produtos finais". Saito et al. (1999) afirmam que os conceitos de agronegócios e cadeias produtivas se confundem em uma mesma ideia, qual seja, de que o desempenho de uma empresa que atua com um produto agrícola ou derivado está diretamente relacionado ao comportamento e ao desempenho das outras firmas que compõem esta cadeia. 
A ideia de interdependência entre firmas que atuam em função de um produto comum é o cerne do conceito de cadeias de suprimentos difundido amplamente por uma série de autores na literatura (STEVENSON e SPRING, 2007; JANVIER-JAMES, 2012; NASLUND e HULTHEN, 2012; ZACHARIA et al. 2014).

Zylbersztajn; Filho (2003) afirmam que estudos tradicionais sobre competitividade em sistemas agroindustriais baseiam-se em custos comparativos e participação de mercado. Os autores reforçam a importância da relação entre coordenação da cadeia e competitividade, sugerindo que estes aspectos sejam considerados em conjunto com outras questões. Esta abordagem é previamente explorada por Farina (1999), que elabora sobre o "significado do conceito de competitividade aplicado a sistemas agroindustriais concretos".

Taylor (2006) discute o impacto da assimetria de informações a respeito das características da demanda à jusante sobre o desempenho operacional da cadeia à montante. Taylor (2006) desenvolve seu trabalho em seis diferentes cadeias de suprimentos agroindustriais. Wagner et al. (2012) também discutem desempenho sob o prisma da gestão da cadeia de suprimentos, afirmando que existe correlação positiva entre a estrutura a partir da qual se estabelece a cadeia de suprimentos com a métrica financeira Retorno sobre os Ativos.

Shukla; Jharkharia (2013) realizam revisão de literatura sobre a gestão da cadeia de suprimentos de produtos agrícolas frescos, afirmando que esta cadeia requer maior atenção no sentido da consolidação do conceito de gestão da cadeia de suprimentos aplicada a ela. Fischer (2013) afirma que a efetiva comunicação e a colaboração positiva entre os membros são fundamentais para a construção de confiança no âmbito da cadeia de produtos agroalimentares na Europa. No mesmo sentido caminham Matopoulos et al. (2007), advogando que o conceito de colaboração na cadeia produtiva é de fundamental importância nas cadeias agroindustriais. Os autores estabelecem relação direta positiva entre colaboração e confiança.

Macharia et al. (2013) discutem os fatores-chaves para a sustentabilidade de cadeias agroalimentares. Os autores afirmam que o consumidor final é quem atribui valor ao produto ou serviço e que, por isto, as cadeias devem estar preparadas para antecipar tendências e atender às necessidades daí advindas. Shukla e Jharkharia (2013, p. 115) afirmam que as cadeias produtivas de produtos agrícolas frescos são mais complexas do que outras cadeias, tendo em vista o caráter perecível dos produtos e as altas flutuações em demanda e preços.
Leat e Revoredo-Giha (2013) afirmam que a vulnerabilidade existente no ambiente da cadeia produtiva de suínos na Escócia foi reduzida pela colaboração horizontal entre produtores e vertical entre processadores e varejistas. Duffy e Fearne (2009) observam que os esforços dos produtores em certificar suas produções em termos de segurança do alimento e bem-estar dos trabalhadores não são remunerados com um preço prêmio na cadeia da carne vermelha no Reino Unido. Afirmam os autores, contudo, que não se trata da falta de reconhecimento por parte do cliente final, mas, sim, de uma maior divulgação da existência deste tipo de certificação. Zhang e Aramyan (2009) propõem uma discussão sobre como integrar a grande massa de pequenos produtores rurais chineses na dinâmica moderna das cadeias produtivas integradas. Os autores chamam a atenção para o papel dos gestores públicos e da iniciativa privada neste desafio.

A revisão de literatura mostra a relevância da análise conjunta dos atores e respectivos relacionamentos estruturados entre eles em função de um produto agroindustralizado ou in natura. Nas palavras de Farina (1999) e Zylbersztajn; Filho (2003), trata-se da importância de se considerar a forma como são construídos e coordenados os relacionamentos no âmbito da cadeia de suprimentos e qual é o impacto disto na competitividade setorial.

\section{METODOLOGIA E PROCEDIMENTO DE COLETA DE DADOS}

Com o intuito de desenvolver e fortalecer a cadeia produtiva do amendoim na região semiárida nordestina, a trading e agroindústria de grãos e oleaginosas Noble Agri e a Empresa Brasileira de Pesquisa Agropecuária (Embrapa Algodão) estabeleceram um Acordo de Cooperação Técnica para a condução do seguinte projeto de pesquisa: "Sistema de produção do amendoim no Vale do São Francisco" (BRASIL, 2015). Esta pesquisa é desenvolvida na área irrigada denominada Sistema Itaparica, região que abrange as margens direita e esquerda do Rio São Francisco nos Estados da Bahia e Pernambuco. Petrolândia, no estado de Pernambuco, foi adotado como município-sede dos trabalhos de campo desenvolvidos no âmbito deste acordo. Maiores detalhes sobre a região são dados no item " 5 " deste trabalho.

Este projeto, em vigor desde março de 2013, entra no seu terceiro ano de execução em 2016. Os trabalhos de pesquisa realizados no âmbito deste acordo têm duas frentes de ações: 
a) Fortalecimento do manejo agrícola da cultura do amendoim: o objetivo desta frente de trabalho é desenvolver o modelo de produção da cultura em ambiente irrigado no semiárido do Nordeste. Para tanto, realizam-se experimentos relacionados ao manejo de irrigação, de pragas e doenças, de adubação e de mecanização agrícola. Além de publicações científicas nas subáreas acima citadas abrangidas pela grande área de Agronomia, esta frente tem por finalidade elaborar e refinar a planilha manejo e custos agrícolas para a cultura do amendoim na região.

b) Fortalecimento da cadeia produtiva do amendoim na região: os objetivos, nesta frente de ação, são desenvolver um modelo de processamento e comercialização do amendoim in natura e dos produtos derivados desta matéria-prima. $\mathrm{O}$ foco desta cadeia produtiva é, em um primeiro momento, o atendimento da demanda da região Nordeste. Em uma segunda etapa, focar-se-á no mercado de exportação via portos nordestinos. Para o cumprimento destes objetivos, realiza-se o mapeamento das necessidades relativas à estruturação e fortalecimento da cadeia e estratégias para o atendimento delas. Alguns pontos permanentes de atenção são:

i. Tecnologia de produção agrícola (máquinas, equipamentos, implementos e defensivos para a produção);

ii. Infraestrutura logística, de beneficiamento póscolheita e de processamento agroindustrial;

iii.Estabelecimento da lógica de comercialização via contratos de compra e venda e eventual financiamento privado da produção;

iv. Fortalecimento do sistema de crédito público para custeio agrícola e investimento em benfeitorias;

v. Incentivo ao agrupamento da base agrícola em associações ou cooperativas;

vi.Proposição de sistemas de produção que contemplem de forma harmoniosa a produção de amendoim com as outras produções agropecuárias locais típicas, tais como ovinocaprinocultura e produção de coco, milho, melancia, abóbora e cebola.

Além dos trabalhos de campo realizado na região do Sistema Itaparica, a equipe se distribui entre os municípios de Campina Grande (PB), sede da Embrapa Algodão; e São Paulo (SP), sede da Noble Agri no Brasil. Na primeira são desenvolvidas atividades que atendem prioritariamente à frente de ação voltada ao manejo agrícola da cultura do amendoim nos seus aspectos agronômicos. Na segunda são elaboradas ações que visem ao atendimento das necessidades requeridas pela frente de ação dedicada ao fortalecimento da cadeia produtiva do amendoim.

Para atender a esta segunda vertente, foram realizadas visitas técnicas e reuniões com os integrantes da cadeia produtiva do amendoim no Estado de São Paulo. Alguns dos principais agentes consultados são: produtores agrícolas, pequenos industriais, grandes agroindústrias, distribuidores de defensivos para a cultura, fabricantes de máquinas agrícolas dedicadas ao manejo da cultura, fabricantes de equipamentos para beneficiamento póscolheita, traders de amendoim e pesquisadores. Agentes integrantes da cadeia produtiva do amendoim oriunda do Sistema Itaparica localizados em outros municípios também são visitados.

Este artigo é derivado dos trabalhos desenvolvidos no âmbito da segunda frente de ação acima listada e de toda a base de dados primária reunida nessa frente. A coleta de dados é feita utilizando-se dois tipos básicos de ferramentas: observação participante e entrevistas não estruturadas. A pesquisa é classificada como do tipo qualitativa, seguindo orientações e conceitos de Vinten (1994); Godoy (1995); Nevid e Maria (1999); Rynes e Gephart Jr. (2004); Sutton (1997).

O Quadro 1 a seguir traz a caracterização dos agentes consultados e das ferramentas utilizadas para a coleta de dados primários que contribuíram para a elaboração deste trabalho.

\section{DISCUSSÃO}

\subsection{Breve Caracterização da Produção de Amendoim no Brasil}

Falar da produção brasileira do amendoim sem enfocar a discussão sobre o Estado de São Paulo é tarefa difícil, já que a produção nacional é fortemente concentrada nessa unidade da federação. Na safra 2014/2015, plantou-se 109.000 hectares no Brasil, dos quais $87 \%$ foram cultivados no Estado (COMPANHIA NACIONAL..., 2015).

A concentração é ainda maior quando a análise se faz regionalmente. Das 347 mil toneladas produzidas pelo país em 2015, o Sudeste foi responsável por praticamente $90 \%$ da área total cultivada, seguido pelo Sul, com quase 5\% (COMPANHIA NACIONAL...; 2015).

A Tabela 1 apresenta a área total produzida de amendoim nas últimas cinco safras por estado produtor.

Organizações Rurais \& Agroindustriais, Lavras, v. 19, n. 1, p. 47-59, 2017 
QUADRO 1 - Caracterização dos agentes consultados e das ferramentas utilizadas para a coleta de dados primários

\begin{tabular}{|c|c|c|c|}
\hline Localização & Agentes consultados (quantidade) & $\begin{array}{l}\text { Instrumento de } \\
\text { coleta de dados }\end{array}$ & $\begin{array}{c}\text { Período da coleta de } \\
\text { dados }\end{array}$ \\
\hline Petrolândia (PE) & $\begin{array}{c}\text { Agricultores familiares (20), atravessadores (3), } \\
\text { representantes do Sindicato dos Trabalhadores e } \\
\text { Trabalhadoras Rural de Petrolândia (STTR) (2), agentes de } \\
\text { Assistência Técnica e Extensão Rural da Empresa do Instituto } \\
\text { Agronômico de Pernambuco (IPA) (3) e da Companhia de } \\
\text { Desenvolvimento dos Vales do São Francisco e Parnaíba } \\
\text { (CODEVASF) (7) e gerente municipal da agência do Banco } \\
\text { do Brasil (1). }\end{array}$ & $\begin{array}{l}\text { Observação } \\
\text { participativa e } \\
\text { entrevistas não } \\
\text { estruturadas. }\end{array}$ & $\begin{array}{l}\text { Entre março de } 2013 \\
\text { e março de } 2016 .\end{array}$ \\
\hline Floresta (PE) & $\begin{array}{c}\text { Gerente regional de agência bancária do Banco do Nordeste } \\
\text { do Brasil (BNB) (1), Técnico de análise de crédito para } \\
\text { custeio do BNB (1). }\end{array}$ & $\begin{array}{l}\text { Entrevista não } \\
\text { estruturada. }\end{array}$ & $\begin{array}{l}\text { Entre março de } 2013 \\
\text { e janeiro de } 2014 .\end{array}$ \\
\hline Recife (PE) & $\begin{array}{c}\text { Atacadistas (4) e superintendente regional do BNB no } \\
\text { Nordeste (1). }\end{array}$ & $\begin{array}{l}\text { Entrevistas não } \\
\text { estruturadas }\end{array}$ & $\begin{array}{c}\text { Entre março de } 2013 \\
\text { e janeiro de } 2014\end{array}$ \\
\hline Aracaju (SE) & Atacadistas (3) & $\begin{array}{l}\text { Entrevistas não } \\
\text { estruturadas }\end{array}$ & $\begin{array}{c}\text { Entre junho de } 2013 \text { e } \\
\text { dezembro de } 2013 .\end{array}$ \\
\hline Pontal (SP) & Pequeno industrial (1) e produtor de amendoim (1) & $\begin{array}{c}\text { Entrevista não } \\
\text { estruturada e } \\
\text { observação } \\
\text { participativa. }\end{array}$ & Agosto de 2013. \\
\hline Dumont (SP) & $\begin{array}{l}\text { Produtor de amendoim (1), corretor para o mercado externo } \\
\text { (1), gerente de agroindústria de amendoim (1) e gerente de } \\
\text { unidade de venda de defensivos para amendoim (1) }\end{array}$ & $\begin{array}{l}\text { Entrevista não } \\
\text { estruturada. }\end{array}$ & $\begin{array}{l}\text { Entre junho de } 2013 \text { e } \\
\text { dezembro de } 2014 \text {. }\end{array}$ \\
\hline Matão (SP) & $\begin{array}{c}\text { Gerentes comerciais de fabricantes de máquinas e } \\
\text { implementos para amendoim (2) }\end{array}$ & $\begin{array}{l}\text { Entrevista não } \\
\text { estruturada. }\end{array}$ & $\begin{array}{l}\text { Entre janeiro de } 2015 \\
\text { e abril de } 2015 \text {. }\end{array}$ \\
\hline Pindorama (SP) & $\begin{array}{c}\text { Gerentes comerciais de fabricantes de máquinas e } \\
\text { implementos para amendoim (1) }\end{array}$ & $\begin{array}{l}\text { Entrevista não } \\
\text { estruturada. }\end{array}$ & $\begin{array}{c}\text { Entre janeiro de } 2015 \\
\text { e abril de } 2015 .\end{array}$ \\
\hline Catanduva (SP) & $\begin{array}{l}\text { Proprietário de fábrica de equipamentos para beneficiamento } \\
\text { de amendoim pós-colheita (1) }\end{array}$ & $\begin{array}{l}\text { Entrevista não } \\
\text { estruturada. }\end{array}$ & $\begin{array}{l}\text { Entre janeiro de } 2015 \\
\text { e abril de } 2015 \text {. }\end{array}$ \\
\hline $\begin{array}{c}\text { TOTAL DE } \\
\text { AGENTES } \\
\text { CONSULTADOS }\end{array}$ & 55 & & \\
\hline
\end{tabular}

Fonte: elaborado pelos autores

Duas são as regiões de cultivo em São Paulo: a região da Alta Mogiana (Ribeirão Preto e Jaboticabal) e a da Alta Paulista (Marília e Tupã) (LOURENZANI e LOURENZANI, 2009, p. 59; BARBOSA et al., 2014, p. 476). A cadeia produtiva do amendoim no Estado é baseada no sistema de rotação de cultura com a canade-açúcar. Com a necessidade de renovar os canaviais periodicamente, usinas e grandes produtores cedem suas terras em arrendamento a interessados em produzir amendoim. O plantio ocorre entre setembro e outubro e a colheita ocorre entre dezembro e janeiro. A semeadura de um novo canavial ocorre imediatamente após a colheita do amendoim.
Sobre a etapa de processamento, pode-se dizer que: O processamento dessa commodity está dividido em dois estágios: processamento primário e processamento secundário. O processamento primário compreende tarefas de limpeza e secagem do produto. Esse estágio é, basicamente, implementado pelos seguintes atores: atacadistas, cooperativas agrícolas/agroindustriais e empresários rurais. Quanto ao processamento secundário, o mesmo é executado pela indústria agroalimentar que utiliza o amendoim como matéria-prima (MP) no processo de fabricação dos seguintes produtos: amendoim salgado, doces, confeitos, pasta/creme de amendoim, amendoim in natura etc (MACHADO, 2006, p. 3; SABES e ALVES, 2009, p. 45). 
TABELA 1 - Área produzida de amendoim no Brasil nas últimas cinco safras

\begin{tabular}{cccccc}
\hline \multirow{2}{*}{ Estado/Região } & \multicolumn{5}{c}{ Área produzida por safra (em mil hectares) } \\
\cline { 2 - 6 } & $\mathbf{2 0 1 0 / 1 1}$ & $\mathbf{2 0 1 1} / \mathbf{1 2}$ & $\mathbf{2 0 1 2} / \mathbf{1 3}$ & $\mathbf{2 0 1 3} / \mathbf{1 4}$ & $\mathbf{2 0 1 4} / \mathbf{1 5}$ \\
\hline NORTE & 1,7 & 2,5 & 1,5 & 0,8 & 2,4 \\
TO & 1,7 & 2,5 & 1,5 & 0,8 & 2,4 \\
NORDESTE & $\mathbf{1 2 , 0}$ & $\mathbf{6 , 1}$ & $\mathbf{5 , 7}$ & $\mathbf{3 , 9}$ & $\mathbf{3 , 3}$ \\
CE & 2,0 & 0,7 & 1,1 & 1,0 & 0,4 \\
PB & 0,6 & 0,3 & 0,5 & 0,3 & 0,3 \\
SE & 1,6 & 1,3 & 1,1 & 1,3 & 1,1 \\
BA & 7,8 & 3,8 & 3,0 & 1,3 & 1,5 \\
CENTRO-OESTE & $\mathbf{3 , 0}$ & $\mathbf{0 , 3}$ & $\mathbf{0 , 2}$ & $\mathbf{0 , 4}$ & $\mathbf{0 , 2}$ \\
MT & 3,00 & 0,30 & 0,20 & 0,40 & 0,20 \\
SUDESTE & $\mathbf{6 0 , 3}$ & $\mathbf{7 8 , 5}$ & $\mathbf{8 3 , 4}$ & $\mathbf{9 4 , 8}$ & $\mathbf{9 7 , 8}$ \\
MG & 3,0 & 2,6 & 2,9 & 2,6 & 2,7 \\
SP & 57,3 & 75,9 & 80,5 & 92,2 & 95,1 \\
SUL & $\mathbf{7 , 7}$ & $\mathbf{6 , 5}$ & $\mathbf{5 , 8}$ & $\mathbf{5 , 4}$ & $\mathbf{5 , 2}$ \\
PR & 3,8 & 2,8 & 2,4 & 2,2 & 2,2 \\
RS & 3,9 & 3,7 & 3,4 & 3,2 & 3,0 \\
\hline NORTE/NORDESTE & $\mathbf{1 3 , 7}$ & $\mathbf{8 , 6}$ & $\mathbf{7 , 2}$ & $\mathbf{4 , 7}$ & $\mathbf{5 , 7}$ \\
\hline CENTRO-SUL & $\mathbf{7 1 , 0}$ & $\mathbf{8 5 , 3}$ & $\mathbf{8 9 , 4}$ & $\mathbf{1 0 0 , 6}$ & $\mathbf{1 0 3 , 2}$ \\
\hline BRASIL & $\mathbf{8 4 , 7}$ & $\mathbf{9 3 , 9}$ & $\mathbf{9 6 , 6}$ & 105,3 & 108,9 \\
\hline
\end{tabular}

Fonte: Companhia Nacional de Abastecimento, 2015

O amendoim produzido em São Paulo pode ter dois destinos principais: a) processamento por pequenos industriais locais que revendem este produto no mercado interno ou para empresas exportadoras ou b) grandes industriais que processam este amendoim em produtos finais de alto valor agregado destinado ao mercado interno e ao mercado internacional. Em ambos os casos, os produtos beneficiados ou industrializados atendem tanto à demanda do Estado de São Paulo quanto das outras unidades da federação, entre elas as da região Nordeste. No primeiro caso, o produto é limpo, seco, classificado e, eventualmente, descascado e torrado. Os grãos podem ser separados em calibres. Podem ser comercializados em sacas de $25 \mathrm{~kg}$ no caso de amendoim na casca, sacas de $50 \mathrm{~kg}$ no caso de amendoim em grão ou em pacotes de 10 e $5 \mathrm{~kg}$ para ambas os tipos de amendoim. No segundo caso, o amendoim é transformado em produtos agroindustrializados de diversos tipos.

\subsection{A Cadeia Produtiva do Amendoim na Região do Sistema Itaparica}

A região da usina hidrelétrica (UHE) Luiz Gonzaga (anteriormente conhecida como usina hidrelétrica de Itaparica) está localizada na chamada seção inferior do médio São Francisco, no semiárido nordestino, entre os estados da Bahia e de Pernambuco (PIMENTEL FILHO, 1988, p. 103). A UHE Luiz Gonzaga forma o reservatório de água de Itaparica, um dos sete principais distribuídos ao longo da bacia do Rio São Francisco (MMA, 2015, p. 7). Os outros reservatórios são: Três Marias, Paulo Afonso IV, Xingó, Paulo Afonso, Moxotó e Sobradinho (MMA, 2015, p. 7).

A área inundada pelo reservatório de Itaparica é de 83.400 ha (CODEVASF, 2010). Cerca de 10 mil famílias foram impactadas pela construção desta barragem (CODEVASF, 2010). Para a realocação das populações urbanas afetadas foram construídas as cidades de Petrolândia (PE), Itacuruba (PE), Rodelas (BA), Barra do Tarrachil (BA) e Glória (BA) (CODEVASF, 2010). Na década de 90, para atendimento da população rural, foram construídos e implantados nove perímetros de irrigação (CODEVASF, 2010). O Quadro 2 traz informações resumidas destes perímetros que compõem o chamado Sistema Itaparica. 
QUADRO 2 - Perímetros irrigados em operação do Sistema Itaparica

\begin{tabular}{|cccc|}
\hline Perímetro & Estado & $\mathbf{N}^{\mathbf{o}}$ de famílias & $\begin{array}{c}\text { Início da } \\
\text { operação }\end{array}$ \\
\hline Caraíbas & $\mathrm{PE}$ & 1.476 & $05 / 1998$ \\
Brígida & $\mathrm{PE}$ & 443 & $02 / 1994$ \\
Icó-Mandantes & $\mathrm{PE}$ & 802 & $03 / 1994$ \\
Barreiras & $\mathrm{PE}$ & 721 & $05 / 1993$ \\
Manga de Baixo & $\mathrm{PE}$ & 25 & $02 / 1987$ \\
Apolônio Sales & $\mathrm{PE}$ & 100 & $05 / 1993$ \\
Pedra Branca & $\mathrm{BA}$ & 711 & $07 / 1995$ \\
Rodelas & $\mathrm{BA}$ & 508 & $05 / 1994$ \\
Glória & $\mathrm{BA}$ & 124 & $04 / 1993$ \\
\hline
\end{tabular}

Fonte: elaborado pelos autores a partir de Codevasf (2010)

A região é caracterizada pela predominância de pequenos agricultores familiares. As áreas irrigadas variam de 2 a 8 ha por família. Contudo, não se pode ignorar os movimentos de compra e venda de lotes entre pequenos produtores e o processo de abertura de novas áreas às margens do Rio São Francisco. Apesar de não significativos para a mudança da estrutura fundiária da região, são ações que originam áreas maiores.

O cultivo de amendoim na região é feito em pequena escala. Não há um período definido (ou safra) para a produção de amendoim. O agricultor é estimulado a plantar quando percebe que o preço que está sendo pago pelo produto é remunerador. A grande questão repousa no fato de que o preço do amendoim muda diariamente. Quando produtor decide fazer o plantio, outros produtores também se sentem motivados a fazêlo pelo mesmo motivo. O resultado deste movimento "manada" é a superoferta de produto em um período concentrado do tempo. Em outras palavras, o preço que era bom há 90 dias, hoje, não remunera os custos de produção.

$\mathrm{O}$ amendoim produzido na região é do tipo vermelho. O plantio raramente é feito com sementes certificadas. Geralmente, o produtor reserva parte da sua produção para um plantio futuro. $\mathrm{O}$ grão produzido atualmente na região é uma mistura de duas variedades de amendoim: o BR1, desenvolvido pela Embrapa Algodão; e o Tatu ST, pelo Instituto Agronômico de Campinas (IAC). Enquanto na região a predominância é do chamado amendoim vermelho, no Estado de São Paulo os produtores cultivam principalmente o chamado IAC Runner 886. Esta variedade, do tipo rasteiro, apresenta produtividade e, por consequência, taxa interna de retorno superior quando comparado com o Tatu ST ou BR1 (VICENTE e SAMPAIO, 2013, p. 20).

A produção de amendoim na região é feita de forma bastante rudimentar. O plantio é feito de forma manual com o uso de equipamentos denominados "matraca". O manejo de defensivos é feito com pulverizadores costais ou barras manuais. Em ambos os casos, não há uso de equipamento de produção individual (EPI). O processo de colheita, dividido nas atividades de arranque e "destaque", também é feito manualmente. Demanda-se entre 25 e 30 pessoas para completar esta última atividade em um hectare em um único dia.

Uma peculiaridade típica da cadeia produtiva do amendoim da região se refere à forma como este produto é vendido. Os produtores fazem a colheita com 90 dias de cultivado, quando o amendoim ainda não está completamente maduro. Antes de realizar a colheita, produtor e comprador acertam preço e volume a ser comercializado. $\mathrm{O}$ amendoim colhido é imediatamente ensacado e, em seguida, carregado nos veículos que o levarão para o próximo destino. Ao amendoim, nestas condições, dá-se o nome de "amendoim verde". No estado de São Paulo, o amendoim é secado em campo por quatro a cinco dias antes de seguir para a próxima etapa da cadeia.

A compra é feita exclusivamente por atravessadores. Não existe a figura do industrial ou atacadista comprador. A unidade de medida adotada para fins de precificação é o saco. Um saco de amendoim verde cheio tem entre 42 e 50 $\mathrm{kg}$. Os preços do saco de amendoim verde variam de $\mathrm{R} \$$ 65 a R \$120. O pagamento geralmente é feito a prazo, já que $\mathrm{o}$ atravessador precisa primeiramente vender o produto e receber por ele. Eventualmente, em temos de escassez de oferta, $\mathrm{o}$ atravessador pode fazer um adiantamento do pagamento no momento em que recebe o amendoim do produtor.

É bastante comum a formação de parceria entre produtor e atravessador para o cultivo de áreas de amendoim. Como o produtor geralmente não possui capital para custear sua lavoura, tampouco tem assistência técnica para acessar linhas de crédito para este fim, ele acaba admitindo o atravessador como parceiro meeiro. Neste sistema, o atravessador disponibiliza sementes e dinheiro para custeio e o produtor entra com sua terra e seu trabalho. Do total arrecadado com a venda da produção, o atravessador tira integralmente o valor desembolsado por ele para 
o custeio da produção. A diferença que se constitui no lucro da operação, se há, é dividida em partes iguais entre produtor e atravessador. Em outros casos, o atravessador apenas disponibiliza as sementes e as cobra na colheita. Neste caso, o pagamento é feito pelo produtor em grãos e, geralmente, o atravessador cobra $100 \%$ de juros sobre o empréstimo. Em outras palavras, para cada saca de amendoim fornecida para semente, $o$ atravessador cobra duas na colheita.

Após a colheita e compra pelo atravessador, o amendoim passa por um processo bastante rudimentar chamado de "cozinhamento" que nada mais é do que o processo de cozinhar o amendoim em solução salgada. Este processo pode ser feito pelo próprio atravessador, em suas próprias dependências; por terceiros contratados; ou pode ser vendido para outro atravessador que possua estrutura para realizar a atividade.

Cumprida a etapa de "cozinhamento", o amendoim pode ser vendido a atacadistas ou diretamente aos consumidores finais. Em mercados de grandes cidades, como Salvador (BA), Aracaju (SE), Maceió (AL), o amendoim verde cozido é geralmente vendido aos atacadistas das Centrais de Abastecimento (CEASA) que, por sua vez, o revendem ao consumidor final. Este consumidor final é preponderantemente formado por pequenos comerciantes ou vendedores individuais. Em ambos os casos, o produto é disponibilizado em sua grande maioria para o consumo nas praias. Em cidades menores, tais como Itabaiana (SE) e Paulo Afonso (BA), este amendoim é vendido diretamente nas feiras municipais, sem passar pela figura do atacadista.

O esquema a seguir coloca em perspectiva a cadeia produtiva do amendoim na região do reservatório de Itaparica, indicando os principais agentes envolvidos e os fluxos físico e financeiro existentes entre eles (Figura 1).

\subsection{Como Fortalecer o Produtor?}

O pequeno produtor encontra-se em posição de grande desvantagem na cadeia produtiva do amendoim. Nos limites da porteira, ele enfrenta toda a dificuldade relativa à falta de acesso à tecnologia e assistência técnica. Além da porteira, sua atuação em termos comerciais fica limitada ao relacionamento com o atravessador. Por outro lado, este último tem uma visão ampla da cadeia, detendo, à montante, uma visão completa da capacidade de oferta da região produtora e, à jusante, da demanda pelo produto.

Quatro ações são apontadas como fundamentais para auxiliar no fortalecimento da posição do produtor dentro da cadeia do amendoim: acesso à tecnologia de produção; acesso a financiamento bancário para custeio e investimento; acesso à infraestrutura logística e de beneficiamento pós-colheita; fortalecimento do espírito associativista e cooperativista.

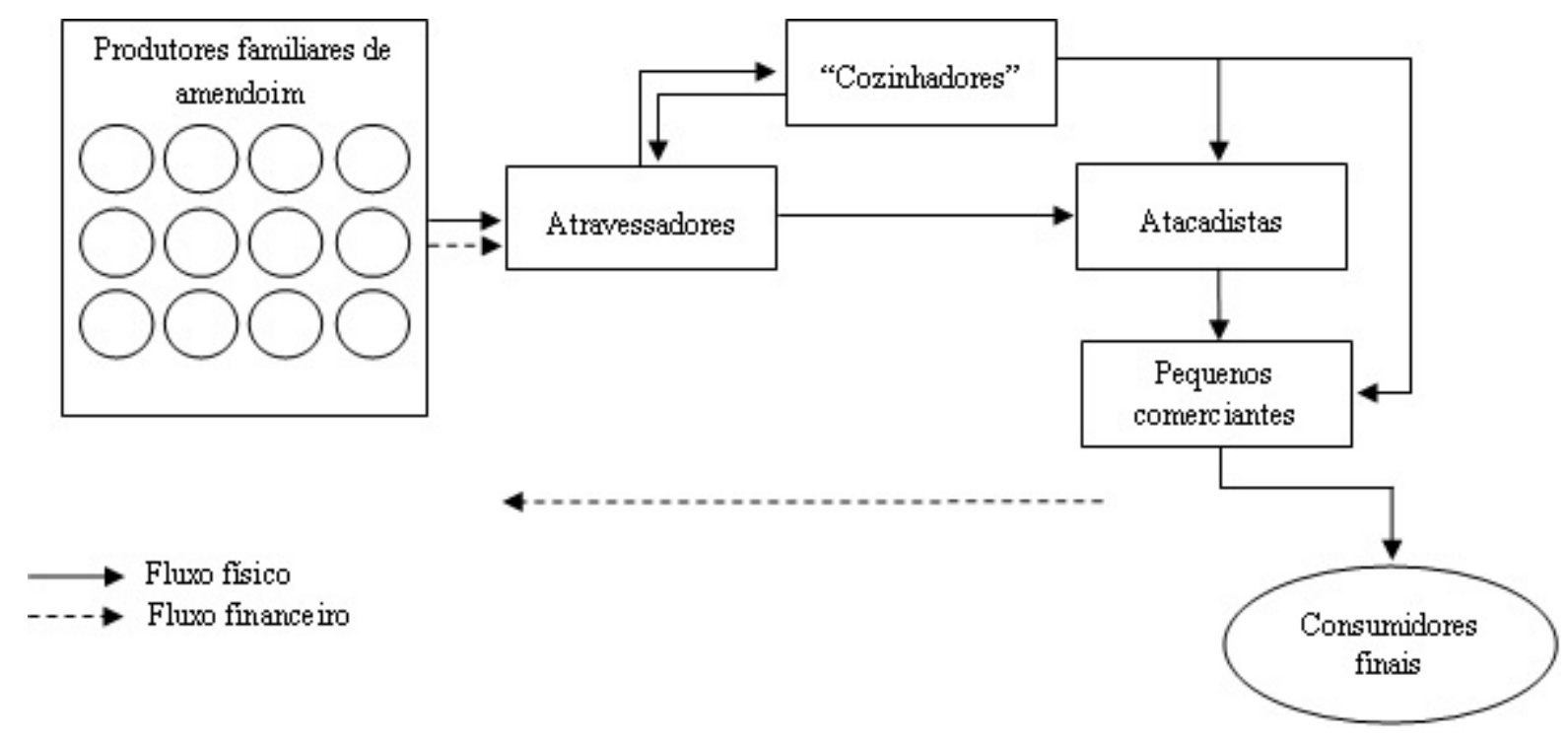

FIGURA 1 - Cadeia produtiva do amendoim na região do Sistema Itaparica Fonte: elaborado pelos autores

Organizações Rurais \& Agroindustriais, Lavras, v. 19, n. 1, p. 47-59, 2017 
Tecnologia de produção se refere a máquinas, equipamentos, defensivos e orientação técnica. A necessidade de utilização de um grande contingente de mão de obra para a realização das diversas atividades que compõem o itinerário técnico de produção faz com que o produtor incorra em elevados custos. A reunião destes custos impacta diretamente o resultado financeiro final da sua atividade. Equipamentos simples como tratores e seus implementos agrícolas para plantio, pulverização e colheita seriam eficazes na resolução desta questão. Levantamentos de campo realizados pelos autores mostram que o produtor gasta entre $\mathrm{R} \$ 7.000,00$ e $\mathrm{R} \$$ $9.000,00$ para produzir um hectare de amendoim verde. Levando-se em consideração a produção média de 90 a 110 sacos de amendoim, pode-se ter, no melhor cenário, um custo de $\mathrm{R} \$ 63,00$ por saca e, no pior, de $\mathrm{R} \$ 100,00$ por saca. No Estado de São Paulo, o produtor rural gasta entre $\mathrm{R} \$ 2.200,00$ e $\mathrm{R} \$ 2.500,00$ por hectare para custear um hectare de amendoim produzindo com o emprego de tecnologia e assistência técnica.

Além da questão econômica, há um aspecto social importante envolvido no elevado uso de mão de obra na lavoura. Quando se fala em 25 a 30 pessoas para colher um hectare de amendoim, está se falando de pessoas que, por falta de opção de renda, precisam trabalhar nesta que é uma atividade exaustiva e degradante. Grande parte destas pessoas são produtores rurais da própria região que não possuem capital de giro para custear sua própria lavoura. Para sobreviver, além de trabalhar em outras roças, esta pessoa arrenda sua área por um valor muito baixo. Depoimentos afirmam que o valor do arrendamento na região fica entre $R \$ 300$ e $\mathrm{R} \$ 600,00$ por hectare. Lembrando que a terra possui irrigação funcional e que não há custo de energia e água. Outro aspecto social relevante se refere à exposição do produtor aos perigos do uso de defensivos agrícolas de forma indiscriminada sem o uso adequado dos EPI. Este tipo de procedimento coloca em cheque, também, a saúde dos consumidores finais que fazem uso do amendoim in natura para alimentação.

Financiamento bancário para custeio e investimento é fundamental para que o agricultor se livre da necessidade de constituir parceria ou de tomar empréstimo de qualquer natureza com o atravessador. Os produtores alegam que, apesar das tentativas, não conseguem acessar o crédito de custeio nos Bancos do Brasil e do Nordeste. Durante a etapa de entrevistas, percebeu-se que o BNB apresenta restrições ao custeio do amendoim em decorrência de três fatores principais: a) não existe uma planilha de custeio agrícola que responda fielmente à realidade produtiva do amendoim na região; b) não existe uma contraparte compradora deste amendoim disposta a firmar um contrato de compra e venda com o produtor e c) o amendoim não está listado entre as culturas aptas ao plantio nos municípios que compõem do Sistema Itaparica conforme o Zoneamento Agrícola de Risco Climático (MINISTÉRIO DA AGRICULTURA..., 2015).

Os três fatores acima indicados não podem ser resolvidos pela comunidade produtora local. $\mathrm{O}$ assunto, que é complexo, precisa ser discutido no âmbito das instituições que atuam na região para que seja rapidamente solucionado. Nenhum dos três pontos levantados pode ser considerado como entraves intransponíveis. A planilha de custo pode ser facilmente disponibilizada por empresas que atuam na região em projetos experimentais com a cultura do amendoim. O Zoneamento Agrícola precisa ser simples e urgentemente adequado de forma a contemplar os municípios do Sistema Itaparica cuja produção é feita sob sistema irrigado. Vários estudos relatam ou demonstram a viabilidade do amendoim na região, inclusive com campos experimentais montados nos municípios do Sistema, tais como Santos (2000), Cruz (2005), Carvalho (2009) e Melo Filho e Santos (2010). A existência de empresas interessadas em investir na cultura do amendoim na região virá a reboque dos ganhos de eficiência dentro da porteira e da organização do sistema de custeio pelas instituições que atuam fora da porteira.

Fomentar o investimento em infraestrutura logística e de beneficiamento é fundamental. $\mathrm{O}$ amendoim verde ensacado logo depois da colheita perde toda a sua capacidade conservação ao longo do tempo. A umidade reunida na vagem verde associada ao calor formado dentro do saco torna-se o ambiente perfeito para a proliferação de fungos e bactérias que irão degradar os grãos ali armazenados. Esta situação fortalece ainda mais o poder de barganha do atravessador perante o produtor. Dispor de estruturas de armazenamento permitiria que o produtor deixasse o amendoim secar no campo, gozando do clima seco e quente da região. Depois de seco, o produto pode ser armazenado em casca por um período de seis meses a um ano, sem que haja prejuízo de qualidade. Associado a isto, estruturas de beneficiamento que permitissem a limpeza, descasque e classificação dos grãos auxiliariam na agregação de valor ao produto e, ao mesmo tempo, abririam novas oportunidades comerciais para o produto oriundo da região. 
Os três pontos acima discutidos se tornam mais facilmente atingíveis se os produtores se organizam em associações ou cooperativas. Porém, este é, sem dúvida, o grande desafio. A capacidade do produtor da região em visualizar a cadeia como um todo é bastante limitada. Com isso, ele não consegue perceber as perspectivas de médio e longo prazo existentes. Sem essa percepção, o produtor não se sente motivado a inovar, já que, para ele, a produção de amendoim é eventual e acontece somente quando o preço é compensador. Sem esta motivação que vem do próprio produtor, qualquer iniciativa que vise fomentar o associativismo ou cooperativismo é inócua.

A necessidade de enxergar a cadeia produtiva do amendoim de forma perene é fundamental. Tão importante quanto isto é convencer o produtor de que, dedicando-se integralmente e profundamente à atividade produtiva, ele pode se beneficiar com rendimentos também perenes. O que se quer propor aqui não é a desconstrução das estratégias de fomento ao cooperativismo e ao associativismo pela apresentação das suas vantagens e benefícios. O que se propõe é que, em conjunto com esta estratégia, coloque-se em prática a estruturação da cadeia, fazendo com que o produtor, individualmente, comece a lucrar perenemente com a cultura. Uma vez que os benefícios financeiros sejam percebidos, ele mesmo buscará alternativas para otimizar os seus ganhos. É neste momento que o associativismo e o cooperativismo ganham espaço. A presença de uma empresa âncora que veja potencial no negócio de amendoim à jusante e que esteja disposta a auxiliar na organização produtiva à montante é um catalisador para que isso ocorra. Na sequência, o quadro resumo com as principais características de cada uma das quatro ações aqui discutidas (Quadro 3).

QUADRO 3 - Quadro resumo das ações de fortalecimento da posição do produtor na cadeia

\begin{tabular}{|c|c|c|}
\hline $\begin{array}{l}\text { Ações de fortalecimento } \\
\text { do produtor na cadeia }\end{array}$ & Descrição & Dificuldades/Limitações \\
\hline $\begin{array}{l}\text { Acesso à tecnologia de } \\
\text { produção }\end{array}$ & $\begin{array}{c}\text { Disponibilizar máquinas, equipamentos e } \\
\text { assistência técnica para a produção agrícola } \\
\text { com custos competitivos. Fundamental que } \\
\text { haja assistência técnica. }\end{array}$ & $\begin{array}{c}\text { Falta de interesse de revendas de máquinas e } \\
\text { equipamentos em instalar escritórios no local devido } \\
\text { à não perenidade dos negócios agrícolas na região. } \\
\text { Falta de assistência técnica especializada capaz de } \\
\text { orientar o produtor sobre equipamentos e locais para } \\
\text { aquisição. }\end{array}$ \\
\hline $\begin{array}{l}\text { Acesso ao financiamento } \\
\text { bancário para custeio e } \\
\text { investimento }\end{array}$ & $\begin{array}{c}\text { Permitir a expansão da produção de } \\
\text { amendoim na região de forma independente } \\
\text { da atuação do atravessador como financiador } \\
\text { ou parceiro. }\end{array}$ & $\begin{array}{c}\text { Ausência de planilha de custeio agrícola do } \\
\text { amendoim na região. } \\
\text { Ausência de contraparte compradora que inspire } \\
\text { confiança e que estabeleça relacionamento contratual } \\
\text { com os produtores. } \\
\text { Imprecisão do Zoneamento Agrícola de Risco } \\
\text { Climático. }\end{array}$ \\
\hline $\begin{array}{l}\text { Investimento em } \\
\text { infraestrutura logística } \\
\text { e de beneficiamento } \\
\text { pós-colheita }\end{array}$ & $\begin{array}{c}\text { Dar condições para o escoamento da } \\
\text { produção de forma racional, explorando } \\
\text { nichos de mercado e agregando valor à } \\
\text { produção. }\end{array}$ & $\begin{array}{l}\text { Agroindústrias especializadas em amendoim não } \\
\text { se interessam em estabelecer-se na região dada a } \\
\text { desestruturação do sistema produtivo. } \\
\text { Produtores não possuem organização, tampouco } \\
\text { capital de giro para um investimento em estrutura de } \\
\text { beneficiamento de amendoim. }\end{array}$ \\
\hline $\begin{array}{l}\text { Fortalecimento do } \\
\text { espírito associativista e } \\
\text { cooperativista }\end{array}$ & $\begin{array}{c}\text { Fortalecer a cadeia produtiva primeiro, } \\
\text { mostrando ao produtor o potencial de ganho } \\
\text { existente nela. A partir daí ele mesmo } \\
\text { buscará estratégias para melhorar ainda } \\
\text { mais o desempenho do seu negócio. O } \\
\text { associativismo ou o cooperativismo podem } \\
\text { ser alternativas. }\end{array}$ & $\begin{array}{l}\text { Produtores não visualizam os benefícios do } \\
\text { associativismo e cooperatismo porque sequer gozam } \\
\text { das benesses básicas de comercializar amendoim } \\
\text { individualmente e lucrar de forma periódica. }\end{array}$ \\
\hline
\end{tabular}

Fonte: elaborado pelos autores 


\section{CONSIDERAÇÕES FINAIS}

Os objetivos deste artigo foram descrever a cadeia produtiva do amendoim na região do reservatório de Itaparica (conhecido como Sistema Itaparica) e trazer propostas que venham a auxiliar o produtor rural no fortalecimento da sua posição dentro desta cadeia. Este é um trabalho qualitativo que se utilizou de dados primários coletados em campo por meio de entrevistas semiestruturadas e observações para a elaboração das discussões. Utilizou-se dos conceitos de cadeias produtivas e desenvolvimento rural para subsidiar as análises aqui realizadas.

A cadeia produtiva do amendoim no Sistema Itaparica é composta pelos seguintes atores: agricultores familiares, atravessador, "cozinhadores", atacadistas, pequenos comerciantes e consumidores finais. Os agricultores familiares têm uma visão muito limitada da cadeia como um todo. A leitura da lógica da cadeia à sua frente é transmitida pelo atravessador, que é o seu único ponto de contato neste sistema. Nesta condição, o produtor é incapaz de identificar, por exemplo, tendências ou oportunidades de mercado advindos do consumidor final. Estudos de Assis e Romeiro (2005), Philereno e Souza (2009), Goulart e Favero (2011), Andrade (2012) e Capellesso e Cazella (2013) discutem a presença dos atravessadores em cadeias produtivas cuja base é composta por pequenos produtores familiares ou não.

Quatro ações são sugeridas para o fortalecimento da posição do produtor na cadeia produtiva do amendoim: acesso à tecnologia de produção, acesso ao financiamento bancário para custeio e investimento, investimento em infraestrutura logística e de beneficiamento pós-colheita e fortalecimento do espírito associativista e cooperativista. Todas estas ações se encontram em um sentido comum, qual seja, dar fluidez e, principalmente, perenidade à cadeia produtiva na região. Havendo um ciclo de produção e comercialização definido, produtor e instituições públicas e privadas, se sentem confiantes para investir na cadeia.

A cadeia produtiva com foco no amendoim na região do Sistema Itaparica e em outras localidades irrigadas do semiárido Nordestino apresenta duas potencialidades: no lado da produção, o clima seco associado à disponibilidade de água via irrigação constituem o cenário ideal para uma cultura que necessita de umidade durante o ciclo produtivo e ambiente seco na fase de colheita e secagem em campo. No lado do mercado consumidor, percebe-se um fluxo cada vez maior de amendoim in natura proveniente do interior de São Paulo para atender à grande demanda das capitais Nordestinas. O estabelecimento de uma base de produção eficiente no semiárido gozaria da vantagem competitiva em termos logísticos para acessar estes mercados quando comparado com a produção paulista. Estes dois tópicos se constituem em lacunas do conhecimento tanto no âmbito da literatura quanto no do mercado. Estudos futuros que se proponham a discuti-los seriam de grande importância.

\section{AGRADECIMENTOS}

Os autores agradecem à empresa Noble Agri e à Embrapa Algodão pela fundação do Acordo de Cooperação Técnica entre as instituições, permitindo o desenvolvimento do projeto "Sistema de produção do amendoim no Vale do São Francisco".

\section{REFERÊNCIAS}

AGÊNCIA NACIONAL DE ÁGUAS. Boletim de Monitoramento dos Reservatórios do Rio São Francisco. Brasília: ANA, 2015. 15 p.

ANDRADE, H. C. P. Organização de produtores rurais para a gestão da cadeia produtiva da mandioca no nordeste paraense: um estudo de caso na Associação de Desenvolvimento Comunitário e Rural Bom Jesus. 2012. 77 f. Dissertação (Mestrado em Administração Pública e de Empresas)-Escola Brasileira de Administração Pública e de Empresas, Fundação Getúlio Vargas, Rio de Janeiro, 2012.

ASSIS, R. L.; ROMEIRO, A. R. Agroecologia e agricultura familiar na região centro-sul do Estado do Paraná. Revista de Economia Rural, Rio de Janeiro, v. 43, n. 1, p. 155177, jan./mar. 2005.

BARBOSA, R. M.; HOMEM, B. F. M.; TARSITANO, M. A. A. Custo de produção e lucratividade da cultura do amendoim no município de Jaboticabal, São Paulo. Revista Ceres, Viçosa, MG, v. 61, n. 4, p. 475-481, jun./ ago. 2014.

BATALHA, M. O. As cadeias de produção agroindustriais: uma perspectiva para o estudo das inovações tecnológicas. Revista de Administração, São Paulo, v. 30, n. 4, p. 4350, out./dez. 1995.

BRASIL. Extrato de Acordo de Cooperação Técnica. Diário Oficial da União, Brasília, DF, 29 jun. 2015. Seção 3, n. 121. 
CAPELlESSO, A. J.; CAZELLA, A. A. Os sistemas de financiamento da pesca artesanal: um estudo de caso no litoral centro-sul catarinense. Revista de Economia e Sociologia Rural, Piracicaba, v. 51, n. 2, p. 275-294, abr./jun. 2013.

CARVALHO, R. M. C. M. O. Avaliação dos perímetros de irrigação na perspectiva da sustentabilidade da agricultura familiar no semiárido pernambucano. 2009. 248 f. Tese (Doutorado em Engenharia Civil)-Centro de Tecnologia e Geociências, Universidade Federal de Pernambuco, Recife, 2009.

CRUZ, J. M. B. Estudo exploratório da capacidade de pagamento da alocação de água em perímetros irrigados: o caso do projeto Icó-Mandantes no Sistema Itaparica - PE. 2005. 47 f. Dissertação (Mestrado Profissional em Economia - Investimento e Empresas)Departamento de Economia, Universidade Federal de Pernambuco, Recife, 2005.

COMPANHIA DE DESENVOLVIMENTO DOS VALES DO SÃO FRANCISCO E DO PARNAÍBA. Sistema Itaparica. Brasília: CODEVASF. 2010. Disponível em: $<$ http://www2.codevasf.gov.br/programas_acoes/sistemaitaparica-1>. Acesso em: 05 jan. 2015.

COMPANHIA NACIONAL DE ABASTECIMENTO. Séries históricas. Rio de Janeiro: CONAB, 2015.

DUFFY, R.; FEARNE, A. Value perceptions of farm assurance in the red meat supply chain. British Food Journal, Bradford, v. 111, n. 7, p. 669-685, 2009.

FARINA, E. M. M. Q. Competitividade e coordenação de sistemas agroindustriais: um ensaio conceitual. Gestão \& Produção, São Carlos, v. 6, n. 3, p. 147-161, dez. 1999.

FISCHER, C. Trust and communication in European agrifood chains. Supply Chain Management: an international journal, Bradford, v. 18, n. 2, p. 208-218, 2013.

GODOY, A. S. Pesquisa qualitativa: tipos fundamentais. Revista de Administração de Empresas, São Paulo, v. 35, n. 3, p. 57-63, maio/jun. 1995.

GOULART, D. F.; FAVERO, L. A. A cadeia produtiva da ovinocaprinocultura de leite na região central do
Rio Grande do Norte: estrutura, gargalos e vantagens competitivas. Revista em Agronegócios e Meio Ambiente, Maringá, v. 35, n. 1, p. 21-36, jan./abr. 2011 .

JANVIER-JAMES, A. M. A new introduction to supply chains and supply chain management: definitions and theories perspectives. International Business Research, Oxford, v. 5, n. 1, p. 194-207, Jan. 2012.

JI, C. et al. An empirical study on governance structure choices in China' s Pork Supply Chain. International Food and Agribusiness Management Review, Essex, v. 15, n. 2, p. 121-152, 2012.

LEAT, P.; REVOREDO-GIHA, C. Risk and resilience in agri-food supply chains: the case of the ASDA PorkLink supply chain in Scotland. Supply Chain Management: an international journal, Bradford, v. 18, n. 2, p. 219-231, 2013.

LOURENZANI, W. L.; LOURENZANI, A. E. B. S. Perspectivas do agronegócio brasileiro de amendoim. Informações Econômicas, São Paulo, v. 39, n. 2, p. 1-14, fev. 2009.

MACHADO, J. G. C. F. Análise das estratégias de marketing das indústrias de processamento de amendoim da região de Tupã-SP. In: CONGRESSO DA SOCIEDADE BRASILEIRA DE ECONOMIA E SOCIOLOGIA RURAL, 44, 2006, Fortaleza. Anais... Fortaleza: Sociedade Brasileira de Economia e Sociologia Rural, 2006. p. 1-20.

MACHARIA, J.; COLLINS, R.; SUN, T. Value-based consumer segmentation: the key to sustainable agri-food chains. British Food Journal, Bradford, v. 115, n. 9, p. 1313-1328, 2013.

MATOPOULOS, A.; VLACHOPOULOS, M.; MANTHOU, V. A conceptual framework for supply chain collaboration: empirical evidence from agri-food industry. Supply Chain Management: an international journal, Bradford, v. 12, n. 3, p. 177-186, 2007.

MELO FILHO, P. A.; SANTOS, R. C. A cultura do amendoim no Nordeste: situação atual e perspectivas. Anais da Academia Pernambucana de Ciência Agronômica, Recife, v. 7, p. 192-208, 2010.

Organizações Rurais \& Agroindustriais, Lavras, v. 19, n. 1, p. 47-59, 2017 
MINISTÉRIO DA AGRICULTURA, PECUÁRIA E ABASTECIMENTO. Ato Portaria n ${ }^{\circ} 35$, jul. 2015. Dispõe sobre os sistemas de suporte ao processo de registro e legalização de empresas da REDESIM. Diário Oficial, Brasília, DF, 2 JUL. 2015.

NASLUND, D.; HULTHEN, H. Supply chain management integration: a critical analysis. Benchmarking: an international journal, Bradford, v. 19, n. 4/5, p. 481-501, 2012.

NEVID, J. S.; MARIA, N. L. S. Multicultural issues in qualitative research. Psychology \& Marketing, Amsterdam, v. 16, n. 4, p. 305-325, July 1999.

PHILERENO, D. C.; SOUZA, O. T. O turismo rural como alternativa de desenvolvimento para a agricultura familiar: investigações sobre suas possibilidades nos municípios de Taquara e Rolante (RS). Ensaios FEE, Porto Alegre, v. 30, nesp., p. 655-682, out. 2009.

PIMENTEL FILHO, G. O impacto ambiental das obras do setor elétrico: o reassentamento da população atingia pela usina de Itaparica. Revista de Admnistração Pública, Rio de Janeiro, v. 22, n. 3, p. 95-110, jul./set. 1988.

RYNES, S.; GEPHART JÚNIOR, R. P. Qualitative research and the "Academy of Management Journal". The Academy of Management Journal, Oxford, v. 47, n. 4, p. 454-462, Aug. 2004.

SABES, J. J. S.; ALVES, A. F. Análise comparativa dos padrões sazonais de comportamento dos preços do amendoim no período de janeiro de 1996 a dezembro de 2005. Revista em Agronegócios e Meio Ambiente, Maringá, v. 2, n. 2, p. 35-62, maio/ ago. 2009.

SAITO, J. R.; FIGUEIREDO, R. S.; BATALHA, M. O. Simulando cadeias agroindustriais. In: WORKSHOP BRASILEIRO DE GESTÃO DE SISTEMAS AGROALIMENTARES, 2, 1999, Ribeirão Preto. Anais... Ribeirão Preto: UFSCar, 1999. p. 1-14.

SANTOS, R. C. BRS 151 L-7: nova cultivar de amendoim para as condições do Nordeste brasileiro. Pesquisa Agropecuária Brasileira, Brasília, v. 35, n. 3, p. 665670, mar. 2000.
SHUKLA, M.; JHARKHARIA, S. Agri-fresh produce supply chain management: a state-of-the-art literature review. International Journal of Operations and Production Management, Washington, v. 33, n. 2, p. 114-158, 2013.

STEVENSON, M.; SPRING, M. Flexibility from a supply chain perspective: definition and review. International Journal of Operations and Production Management, Washington, v. 27, n. 7, p. 685-713, 2007.

SUTTON, R. I. The virtues of closet qualitative research. Organization Science, Providence, v. 8, n. 1, p. 97-106, Jan./Feb. 1997.

TAYLOR, D. H. Demand management in agri-food supply chains: an analysis of the characteristics and problems and a framework for improvement. The International Journal of Logistics Management, Elmsford, v. 17, n. 2, p. 163-186, 2006.

VICENTE, J. R.; SAMPAIO, R. M. Impactos econômicos e inovações agrícolas: o caso das cultivares de amendoim no Estado de São Paulo. Revista de Economia Agrícola, São Paulo, v. 60, n. 2, p. 9-22, jul./dez. 2013.

VINTEN, G. Participant observation: a model for organizational investigation? Journal of Managerial Psychology, Amsterdam, v. 9, n. 2, p. 30-38, 1994.

WAGNER, S. M.; GROSSE-RUYKEN, P. T.; ERHUN, F. The link between supply chain fit and financial performance of the firm. Journal of Operations Management, Amsterdam, v. 30, n. 4, p. 340-353, May 2012.

ZACHARIA, Z. G.; SANDERS, N. R.; FUGATE, B. S. Evolving functional perspectives within supply chain management. Journal of Supply Chain Management, Tempe, v. 50, n. 1, p. 73-88, Jan. 2014.

ZHANG, X.; ARAMYAN, L. H. A conceptual framework for supply chain governance: an application to agri-food chains in China. China Agricultural Economic Review, China, v. 1, n. 2, p. 136-154, 2009.

ZYLBERSZTAJN, D; MACHADO FILHO, C. A. P. Competitiveness of meat agri-food chain in Brazil. Supply Chain Management: an international journal, Bradford, v. 8 , n. 2 , p. $155-165,2003$. 